\title{
Prognostic factors in left-sided endocarditis: results from the andalusian multicenter cohort
}

\author{
Juan Gálvez-Acebal ${ }^{*}$, Jesús Rodríguez-Baño ${ }^{1}$, Francisco J Martínez-Marcos ${ }^{2}$, Jose M Reguera ${ }^{3}$, Antonio Plata ${ }^{3}$, \\ Josefa Ruiz ${ }^{4}$, Manuel Marquez ${ }^{4}$, Jose M Lomas ${ }^{2}$, Javier de la Torre-Lima ${ }^{5}$, Carmen Hidalgo-Tenorio ${ }^{6}$, \\ Arístides de Alarcón ${ }^{7}$, \\ the Grupo para el Estudio de las Infecciones Cardiovasculares de la Sociedad Andaluza de Enfermedades \\ Infecciosas (SAEI)
}

\begin{abstract}
Background: Despite medical advances, mortality in infective endocarditis (IE) is still very high. Previous studies on prognosis in IE have observed conflicting results. The aim of this study was to identify predictors of in-hospital mortality in a large multicenter cohort of left-sided IE.

Methods: An observational multicenter study was conducted from January 1984 to December 2006 in seven hospitals in Andalusia, Spain. Seven hundred and five left-side IE patients were included. The main outcome measure was in-hospital mortality. Several prognostic factors were analysed by univariate tests and then by multilogistic regression model.
\end{abstract}

Results: The overall mortality was 29.5\% (25.5\% from 1984 to 1995 and 31.9\% from 1996 to 2006; Odds Ratio 1.25; 95\% Confidence Interval: 0.97-1.60; $p=0.07$ ). In univariate analysis, age, comorbidity, especially chronic liver disease, prosthetic valve, virulent microorganism such as Staphylococcus aureus, Streptococcus agalactiae and fungi, and complications (septic shock, severe heart failure, renal insufficiency, neurologic manifestations and perivalvular extension) were related with higher mortality. Independent factors for mortality in multivariate analysis were: Charlson comorbidity score (OR: 1.2; 95\% Cl: 1.1-1.3), prosthetic endocarditis (OR: 1.9; Cl: 1.2-3.1), Staphylococcus aureus aetiology (OR: $2.1 ; \mathrm{Cl}: 1.3-3.5)$, severe heart failure (OR: $5.4 ; \mathrm{Cl}$ : 3.3-8.8), neurologic manifestations (OR: 1.9; Cl: 1.2-2.9), septic shock (OR: 4.2; Cl: 2.3-7.7), perivalvular extension (OR: 2.4; Cl: 1.3-4.5) and acute renal failure (OR: 1.69; Cl: 1.0-2.6). Conversely, Streptococcus viridans group etiology (OR: 0.4; Cl: 0.2-0.7) and surgical treatment (OR: 0.5; Cl: 0.3-0.8) were protective factors.

Conclusions: Several characteristics of left-sided endocarditis enable selection of a patient group at higher risk of mortality. This group may benefit from more specialised attention in referral centers and should help to identify those patients who might benefit from more aggressive diagnostic and/or therapeutic procedures.

\section{Background}

The diagnostic and therapeutic advances of recent years have only marginally reduced mortality associated with infective endocarditis (IE). Thus, a $30 \%$ mortality rate was reported after the introduction of antimicrobial therapy [1] but 50 years later, despite the introduction of new antimicrobial agents and advances in surgical therapy, and even though some recent publications

\footnotetext{
* Correspondence: jga3156@yahoo.es

${ }^{1}$ Infectious Diseases Section, University Hospital Virgen Macarena, Sevilla. Spain
}

C 2010 Gálvez-Acebal et al; licensee BioMed Central Ltd. This is an Open Access article distributed under the terms of the Creative Commons Attribution License (http://creativecommons.org/licenses/by/2.0), which permits unrestricted use, distribution, and reproduction in any medium, provided the original work is properly cited. found mortality rates lower than $20 \%[2,3]$, it remains around $20-40 \%$ in most series $[4,5]$.

During the past few years, several published epidemiological studies have identified a number of prognostic factors related to higher mortality, such as advanced age [6,7], female gender [6], prosthetic valve endocarditis [6,7], Staphylococcus aureus aetiology [6-10], comorbidity [6,9], analytical data (leucocytosis [11], hypoalbuminemia [11], C-reactive protein values [12] and elevated ERS [7]), and the development of various complications (heart failure [6-9,12,13], cerebral embolism [7,10,12] 
renal insufficiency [6], septic shock [10] and paravalvular extension [7]). However, studies investigating prognostic factors for IE frequently have methodological flaws since they are based on short retrospective series, the experience of a single hospital, or use non-uniform diagnostic criteria. Moreover, many of these studies are performed in referral centers, where the most complicated cases are usually treated [14]. More accurate information may be obtained from prospective multicenter studies, in which it is possible to include a large number of cases based on strict diagnostic criteria. Knowledge of potentially modifiable risk factors should help to identify those patients who might benefit from more aggressive diagnostic and/or therapeutic procedures [15]. Our objective was to investigate factors associated with a worse prognosis in a multicenter cohort of left-sided IE patients.

\section{Methods}

\section{Study design and patients}

All patients diagnosed of IE in seven hospitals in Andalusia (South of Spain) were consecutively registered in a uniform database from January 1984 throughout December 2006. Five are tertiary referral hospitals for cardiac surgery and 2 are community hospitals; the latter transferred patients evaluated as being at higher risk for mortality to the referral centres. All cases of leftsided IE defined according to Duke criteria [16] with later modifications [17] for definite and possible IE were included. Patients registered before 1994 were retrospectively evaluated for diagnostic criteria. In the case of relapses, only the first episode was included. Cases with insufficient follow-up (not longer than one month) were excluded.

\section{Variables and definitions}

Data were recorded prospectively by members of the Infectious Diseases services or units in the participating centres using a structured questionnaire and introduced into a common database. The cases were detected from routine review of microbiology, echocardiography and surgery reports. The primary outcome measure was overall mortality during hospitalisation (in-hospital death). All cases with no signs of infection and a negative post-antimicrobial treatment culture were considered cured. Relapses, defined as an IE episode occurring within 6 months of a previous one and caused by the same microorganism, were also recorded. Recurrence was defined as a new IE episode in the same patient and related to a different microorganism. The following independent variables were recorded: age, sex, health care-associated acquisition, type and severity of underlying comorbidity evaluated according to the age-adjusted Charlson index [18], duration of symptoms before diagnosis, septic shock, heart failure, embolism, neurologic manifestations, acute renal failure, echocardiographic findings (vegetations and size, abscess, prosthetic dehiscence and valvular dysfunction), microbiologic data (microorganisms isolated from blood cultures and/or valve tissues, and serologic tests), and treatment (medical and surgical). For analysis purposes, the study period was arbitrary divided in two: 1984 - 1995 and 1996 2006.

The additive euroSCORE index [19] were calculated for operative risk evaluation in every patient. Predisposing valvulopathy was defined as any previous valvular heart lesion that predispose to IE. Prosthetic endocarditis was considered as early if it occurred within one year of valve implantation and late otherwise. Heart failure was defined according to Framingham's criteria [20] and was evaluated at admission and during evolution. Septic shock was defined according to standard criteria [21]. Perivalvular extension was defined as the presence of an abscess and/or fistula and/or pseudoaneurism diagnosed by echocardiogram, in surgery or at autopsy. A major symptomatic embolism was considered if the central nervous system, spleen or extremities were affected. Neurologic manifestations were considered only in patients with clinical manifestations related to encephalopathy, meningitis, cerebral infarct or a haemorrhage, and demonstrated by cerebrospinal fluid analysis, radiological test or at autopsy. Severe renal insufficiency was defined as a serum creatinin level $>2.5 \mathrm{mg} / \mathrm{dl}$. Left-sided IE were considered nosocomially acquired using previously published criteria [22]. After 1994 transesophagic echocardiography (TEE) was performed in cases with a high clinical probability of IE when transthoracic echochardiography (TTE) was not diagnostic, and routinely in prosthetic IE or when cardiac complications were suspected.

This study was approved by ethical and research committees of all participating hospitals.

\section{Statistical analysis}

The association of the different variables with the outcome was firstly analysed by univariate analysis. Continuous variables were expressed like mean \pm standard deviation or like median and interquartile rank in case of abnormal distribution and were analysed using the Student's T test or the Mann-Whitney U test as appropriate. Categorical variables were expressed like absolute numbers and proportion of cases and were compared using the chi-squared or Fisher's test when appropriate. Relative risks with 95\% confidence interval for mortality were calculated. Then, multivariate analysis was performed using logistic regression. The multivariate model was built including all variables with a significant association in univariate analysis $(\mathrm{p}<0.05)$ and those considered potentially clinically relevant; modification effects between variables were also studied. The 
selection of variables was performed using a stepwise backward procedure. All statistical studies were performed using SPSS software (v12.0, Chicago, IL, USA).

\section{Results}

\section{General features of the cohort}

Seven hundred and five case-patients of left-sided IE were included in the study. Only other 8 patients were excluded because insufficient evolution data. Among included cases, $624(88 \%)$ were considered as definite and $81(12 \%)$ as possible IE. Mean $( \pm$ SD) post-hospitalisation follow-up was $15.75 \pm 25.05$ months (range: 1 192). The median age of the patients was 56 years (interquartile rank from 41 to 68 years), only 5 patient were $\leq 15$ years old. Four hundred and eighty six (69\%) patients were male. Native valves were affected in 534 (76\%) cases. Of 171 patients (24\%) with prosthetic IE, 69 were considered early and 102 late. The aortic valve was affected in 320 (45\%) cases, the mitral valve in 299 $(42 \%)$, and both valves were affected in $86(11 \%)$ patients. Globally, $488(69 \%)$ had a predisposing valvulopathy for IE and $57(8 \%)$ had suffered at least one previous episode of IE. The mean $( \pm \mathrm{SD})$ age-adjusted Charlson index was $1.84 \pm 2.27$ (range: $0-10$ ), and the most frequent underlying diseases were: diabetes mellitus (35 patients, $5 \%)$, non-valvular heart diseases (32 patients, $5 \%$ ), chronic liver diseases (32 patients $5 \%$ ); neoplasia (28 patients, $4 \%$ ); chronic renal insufficiency (24 patients, $3 \%$ ); and chronic lung disease (16 patients, $2 \%)$. Forty-six patients (7\%) were intravenous drug abusers.

Aetiology was established by isolating the causative microorganism from blood culture in 598 (85\%) patients, a surgically-explanted valve culture in $70(10 \%)$ and by serologic test in 35 (5\%). Streptococcus viridans group was the most frequent microorganism isolated, followed by Staphylococcus aureus, coagulase-negativestaphylococci and Enterococcus spp. (table 1). In 71 cases $(10 \%)$, aetiology was unknown, because all microbiological studies were negatives.

Echocardiography was performed on 698 patients: TTE alone on 409 (58\%), TEE alone on $16(2 \%)$ and both TTE and TEE on 273 patients (39\%). In 7 patients, no echocardiographic study was performed because endocarditis was not suspected until surgery or necropsy. Overall, TTE was diagnostic in 448 of 682 patients $(66 \%)$ in which it was performed, and TEE in 251 of 289 (87\%). In 156 patients where a TTE study was not diagnostic, a TEE study obtained a defined diagnosis of IE in 122 (78.2\%).

Many patients developed complications: 282 (40\%) had cardiac failure, 194 (27\%) presented neurologic manifestations, 280 (40\%) had systemic embolisms (in 147 cases, the central nervous system was affected), 190
(27\%) developed acute renal insufficiency, 86 (12.2\%) septic shock, and 87 (13\%) perivalvular extension (perivalvular abscess, 70; fistula 15; and pseudoaneurism 2).

Valvular surgery was performed in 269 patients (38\%). The most frequent indications for surgery were severe heart failure (in 171 patients, 63.5\%), followed by valve dysfunction (37 patients, 13.7\%), persistent sepsis (21 patients, $7.8 \%$ ), and perivalvular extension (8 patients, $2.9 \%$ ). There were several indications for surgery in 27 patients $(10.0 \%)$. Fifty and three $(7.5 \%)$ was not operated because of critical situation and high risk intervention.

\section{Prognosis}

Two hundred and eight patients died during their hospital stay (mortality rate, 29.5\%). Relapses occurred in 17 patients $(2.4 \%)$, and the 480 remaining cases $(68 \%)$ were considered cured. Principal causes of death was: heart failure in 44 patients $(21.5 \%)$ sepsis in 28 (13.4\%) neurologic complications in $22(10.5 \%)$, and by several of these complications in $71(34.1 \%)$.

The variables significantly associated with increased mortality in univariate analysis were age, nosocomial acquisition, severity of underlying disease, chronic liver disease, prosthetic valve endocarditis, early prosthetic valve endocarditis, S. aureus, Streptococcus agalactiae and fungal aetiology, lesser duration of symptoms before diagnosis, development of septic shock, progressive or refractory heart failure, acute renal insufficiency, the presence of cardiac abscess or fistula, and non performed surgery although indicated because of high associated risk (tables 2 and 3). Conversely, Streptococcus viridans group aetiology was associated with lower mortality rates. The final multivariate model is shown in table 4; the $\mathrm{p}$ value of the Hosmer-Lemeshow goodnessof-fit test for the final model was 0.514 .

\section{Discussion}

Mortality rate of left-sided IE remains high. Although rates lower than $20 \%$ have been reported $[7,22,23]$, they usually range between 20 and 30\%[4,5] and are even higher in some subgroups; mortality rates of $50 \%$ has been reported in early prosthetic valve IE due to $S$. aureus [24]. Crude mortality rate in our series was $29.5 \%$, an intermediate figure considering the intrinsic features of the patients, the number of complicated cases, and the length of the study period. Considering the evolution of mortality over time, we observed a non-significant upward trend, probably related to an increased percentage of cases caused by more virulent organisms such as S. aureus, and to a higher frequency of elderly patients with comorbidities.

Previous studies about the prognosis of IE have often been incomplete in their collection of risk factors, have included heterogeneous subtypes (ie, left-side and rightside endocarditis) or have been carried out on patients 
Table 1 Microbiologic aetiology by IE type in $\mathbf{7 0 5}$ patients with left-sided infective endocarditis.

\begin{tabular}{|c|c|c|c|c|}
\hline Microorganism & Native & $\begin{array}{c}\text { Early } \\
\text { Prosthetic }\end{array}$ & $\begin{array}{c}\text { Late } \\
\text { Prosthetic }\end{array}$ & Total \\
\hline \multicolumn{5}{|l|}{ Streptococci } \\
\hline Streptococcus viridans group & $132(25)$ & $3(4)$ & $21(21)$ & $156(22)$ \\
\hline Enterococcus spp & $60(11)$ & $6(9)$ & $12(12)$ & $78(11)$ \\
\hline Streptococcus bovis & $18(3)$ & 0 & $1(1)$ & $19(3)$ \\
\hline Streptococcus agalactiae & $12(2)$ & 0 & $3(3)$ & $15(2)$ \\
\hline Others & $21(4)$ & 0 & $3(3)$ & $24(3)$ \\
\hline \multicolumn{5}{|l|}{ Staphylococci } \\
\hline Staphylococcus aureus & $106(21)$ & $11(16)$ & $12(14)$ & $137(19)$ \\
\hline Coagulase-negative Staphylococci & $45(8)$ & $34(50)$ & $23(23)$ & $102(15)$ \\
\hline Gramnegative bacilli & $14(3)$ & $1(2)$ & $1(1)$ & $16(2)$ \\
\hline HACEK Group & $5(1)$ & 0 & $4(4)$ & $9(1)$ \\
\hline Brucella spp & $12(2)$ & 0 & 0 & $12(2)$ \\
\hline Coxiella burnetii & $12(2)$ & 0 & $6(6)$ & $18(3)$ \\
\hline Fungi & $5(1)$ & $3(4)$ & $1(1)$ & $9(1)$ \\
\hline Other & $12(2)$ & $4(6)$ & $4(4)$ & $20(3)$ \\
\hline Polymicrobial & $19(4)$ & 0 & 0 & $19(3)$ \\
\hline Unknown & $53(10)$ & $7(10)$ & $11(11)$ & $71(10)$ \\
\hline Total & $534(100)$ & 69 (100) & $102(100)$ & 705 \\
\hline
\end{tabular}

Data are expressed as number of cases (\%).

treated in a single reference center. Only few multicenter cohort with multivariate analysis studies including large numbers of patients have been reported $[6,7,9,10,13,25]$, of which one included only patients admitted to the ICU [10] and another only patients with prosthetic valve IE [12]. This prospective multicenter study includes cases from both referral and community hospitals. We also include IE in both prosthetic and native valves and we have included most factors found in previous studies, such as patient-related variables, aetiology, and the development of different complications.

A Charlson index of more than 2 points has been reported to be an independent risk factor for mortality in previous studies $[6,9]$. We used the age-adjusted index on the grounds that age may be related to prognosis [26] and also found it to be related with increased risk of death. Many of our patients had more than one underlying condition. Insulin-dependent diabetes mellitus has been observed to be a risk factor in one study [27] but we did not find such association in ours. On the other hand, a very high mortality rate was found among patients with chronic liver disease (47\%), similarly to what has been reported in another Spanish series [28].

Prosthetic valve IE, particularly early episodes and those caused by $S$. aureus, are usually associated with a worse prognosis than native valve IE [23,29]. Crude mortality of prosthetic valve IE in our series was almost
3 times higher than for native IE, corroborating the results of previous studies $[12,29,30]$. Furthermore, $S$. aureus was independently associated with increased mortality, whilst Streptoccocus viridans group was a protective factor. Our results confirm another recent collaborative multicenter study where mortality for IE was higher when due to $S$. aureus $(22.4 \%$ vs $14.6 \%$ for other aetiologies)[30]; association of this microorganism with life-threatening complications, such as septic shock and neurologic manifestations have also been reported [31]. All these data emphasise the prognostic relevance of this microorganism in IE.

Heart failure has been found to be a strong marker for increased mortality in most studies [8]. In contrast to Chu et al [7], we did not find heart failure at admission to be associated with a worse prognosis. A possible explanation for this is that heart failure at admission, when due to treatable disorders such as arrhythmia, fluid overload, etc, may be controlled by medical treatment. On the other hand, the development of moderate to severe heart failure during evolution was related to increased mortality. We think that development of heart failure during evolution is probably due in most cases to progressive valve dysfunction, which would only be modifiable by surgery. In fact, surgery was a protective factor in our study. Surgical treatment was a protective factor in only two previous studies [8,9], particularly in complicated cases with severe heart failure [32]. The fact that surgery is an independent protective factor for 
Table 2 Univariate analysis of in-hospital-mortality: patient characteristics and etiology.

\begin{tabular}{|c|c|c|c|c|c|c|}
\hline Variable & & $\begin{array}{c}\text { Alive } \\
\mathrm{N}=497\end{array}$ & $\begin{array}{c}\text { Deaths } \\
\mathrm{N}=208\end{array}$ & RR & $95 \% \mathrm{Cl}$ & $p$ \\
\hline Age (years) & Mean \pm SD & $51.6 \pm 17$ & $58.8 \pm 16$ & - & - & $<0.001$ \\
\hline \multirow[t]{2}{*}{ Gender } & Male & $345(71)$ & $141(29)$ & 1.07 & $0.76-1.52$ & 0.367 \\
\hline & Female & $152(69.4)$ & $67(30.6)$ & & & \\
\hline \multirow[t]{2}{*}{ Period } & 1984-1995 & $196(74.5)$ & $67(25.5)$ & 1.25 & $0.97-1.60$ & 0.070 \\
\hline & $1996-2006$ & $301(68.1)$ & $141(31.9)$ & & & \\
\hline \multirow[t]{2}{*}{ Hospital } & Tertiary & $451(69.3)$ & 200(30.7) & 2.07 & $1.08-3.96$ & 0.008 \\
\hline & Community & $46(85.2)$ & $8(14.8)$ & & & \\
\hline \multirow[t]{2}{*}{ Nosocomial } & Yes & $55(53.4)$ & $48(46.6)$ & 1.75 & $1.37-2.24$ & $<0.001$ \\
\hline & No & $442(73.4)$ & $160(26.6)$ & & & \\
\hline \multirow[t]{2}{*}{ Comorbidity } & Yes & $259(64.4)$ & $143(35.6)$ & 1.65 & $1.28-2.13$ & $<0.001$ \\
\hline & No & $238(78.8)$ & $65(21.5)$ & & & \\
\hline \multirow[t]{2}{*}{ Charlson's index } & Mean \pm SD & $1.56 \pm$ & $2,50 \pm$ & & & $<0.001$ \\
\hline & & 2.15 & 2.42 & & & \\
\hline \multirow[t]{2}{*}{ Diabetes mellitus } & Yes & $24(68.8)$ & $11(31.4)$ & 1.06 & $0.64-1.76$ & 0.464 \\
\hline & No & $473(70.6)$ & $197(29.4)$ & & & \\
\hline \multirow[t]{2}{*}{ Chronic renal insufficiency } & Yes & $14(58.3)$ & $10(41.7)$ & 1.43 & $0.88-2.33$ & 0.184 \\
\hline & No & $483(70.9)$ & $198(29.1)$ & & & \\
\hline Chronic liver & Yes & $17(53.1)$ & $15(46.9)$ & 1.63 & $1.10-2.40$ & 0.027 \\
\hline Disease & No & $480(71,3)$ & $193(28,7)$ & & & \\
\hline \multirow[t]{2}{*}{ Valve involved } & Aortic & 223 (71.9) & $118(29.3)$ & 1.02 & $0.81-1.28$ & 0.456 \\
\hline & Mitral & $274(69.3)$ & $90(29.1)$ & & & \\
\hline \multirow[t]{2}{*}{$>1$ valve involved } & Yes & 49 (64.5) & $27(35.5)$ & 1.23 & 0.89-1.71 & 0.223 \\
\hline & No & $448(71,2)$ & $181(28,8)$ & & & \\
\hline \multirow[t]{2}{*}{ Valve type } & Prosthetic & $104(60.8)$ & 67 (39.2) & 1.48 & 1.17-1.87 & 0.001 \\
\hline & Native & $393(73.6)$ & $141(26.4)$ & & & \\
\hline \multirow[t]{2}{*}{ Prosthetic type } & Early & $33(47.8)$ & $36(52.2)$ & 1.93 & $1.48-2.50$ & $<0.001$ \\
\hline & Late & $464(73)$ & $172(27)$ & & & \\
\hline \multirow[t]{2}{*}{ S. aureus } & Yes & $70(51.1)$ & $67(48.7)$ & 1.96 & $1.57-2.46$ & $<0.001$ \\
\hline & No & $427(75.2)$ & $141(24.8)$ & & & \\
\hline \multirow[t]{2}{*}{ S. viridans group } & Yes & $140(89.7)$ & $16(10.3)$ & 0.29 & $0.18-0.47$ & $<0.001$ \\
\hline & No & $357(65)$ & $192(35)$ & & & \\
\hline \multirow[t]{2}{*}{ Coagulase-negative Staphylococci } & Yes & $64(62.7)$ & $38(37.3)$ & 1.32 & $0.99-1.75$ & 0.040 \\
\hline & No & $433(71.8)$ & $170(28.2)$ & & & \\
\hline \multirow[t]{2}{*}{ Enterococcus spp. } & Yes & $52(66.7)$ & $26(33.3)$ & 1.14 & $0.1-1.60$ & 0.254 \\
\hline & No & $445(71)$ & $182(29)$ & & & \\
\hline \multirow[t]{2}{*}{ S. agalactiae } & Yes & $7(46.7)$ & $8(53.3)$ & 1.84 & $1.12-2.99$ & 0.044 \\
\hline & No & $490(71)$ & $200(29)$ & & & \\
\hline \multirow[t]{2}{*}{ Fungal } & Yes & $2(22.2)$ & $7(77.8)$ & 2.69 & $1.86-3.89$ & 0.004 \\
\hline & No & $495(71.1)$ & $301(28.9)$ & & & \\
\hline
\end{tabular}

Data are expressed as number of cases (\%) except when indicated.

mortality in our study is possibly related to the high number of complicated cases included with heart failure due to valvular dysfunction. However this date must be interpreted with caution since this is an observational study; in another recent study [8], surgery during episode of IE either was associated with better prognosis when this variable was analysed in a multivariable regression modelling.
The exact impact of surgical treatment in IE is controversial and difficult to assess, since evidence is based in observational studies but not in clinical trials. Some new methods of analysis, such as the use of propensity score, have been applied in some studies in order to improve the control of confounding. However the results of these studies are conflicting probably because of methodological differences, as has been recently reviewed [33]. 
Table 3 Univariate analysis of in-hospital-mortality: echocardiographic characteristics, complications and treatment.

\begin{tabular}{|c|c|c|c|c|c|c|}
\hline Variable & & Alive $N=497$ & $\begin{array}{c}\text { Deaths } \\
\mathrm{N}=208\end{array}$ & RR & $95 \% \mathrm{Cl}$ & $P$ \\
\hline Duration of symptoms (days) & Mean \pm SD & $40.5 \pm 84$ & $20.3 \pm 27.4$ & & & $<0.001$ \\
\hline \multirow[t]{2}{*}{ Septic shock } & Yes & $24(27.9)$ & $62(72.1)$ & 3.05 & $2.51-$ & $<0.001$ \\
\hline & No & $473(76.4)$ & $146(23.6)$ & & 3.70 & \\
\hline Severe heart failure & Yes & $101(57.1)$ & $76(42.9)$ & 1.75 & $1.59-$ & $<0.001$ \\
\hline (Admission) & No & $397(75,1)$ & $131(24,9)$ & & 3.25 & \\
\hline Severe heart failure & Yes & $150(53.2)$ & $132(46.8)$ & 2.60 & $2.05-$ & $<0.001$ \\
\hline (Evolution) & No & $347(82)$ & $76(18)$ & & 3.31 & \\
\hline \multirow[t]{2}{*}{ Renal insufficiency } & Yes & $99(52.1)$ & $91(47.9)$ & 2.15 & $1.79-$ & $<0.001$ \\
\hline & No & $397(77.8)$ & $113(22.2)$ & & 2.69 & \\
\hline Neurologic & Yes & $113(57.9)$ & $82(42.1)$ & 1.70 & $1.36-$ & $<0.001$ \\
\hline manifestations & No & $384(75.3)$ & $126(24.7)$ & & 2.12 & \\
\hline \multirow[t]{2}{*}{ Perivalvular Extension } & Yes & $44(51.2)$ & $42(48.8)$ & 1.82 & $1.41-2.34$ & $<0.001$ \\
\hline & No & $453(73.2)$ & $166(26.8)$ & & & \\
\hline \multirow[t]{2}{*}{ Vegetations in echocardiography } & Present & $362(68.8)$ & $164(31.2)$ & 1.29 & $0.95-$ & 0.075 \\
\hline & Absent & $133(75.4)$ & $44(24.6)$ & & 1.68 & \\
\hline \multirow[t]{2}{*}{ Vegetations > 20 mm* } & Yes & 35 (63.6) & $20(36.4)$ & 1.40 & $0.96-$ & 0.070 \\
\hline & No & $402(74)$ & $141(26)$ & & 2.04 & \\
\hline Additive euro SCORE & Mean \pm SD & $7.86 \pm 3.65$ & $12.39 \pm 3.07$ & & & $<0.001$ \\
\hline \multirow[t]{2}{*}{ Surgical treatment } & Yes & $180(67.2)$ & $88(32.8)$ & 1.19 & $0.95-$ & 0.07 \\
\hline & No & $317(72.5)$ & $120(27.5)$ & & 1.50 & \\
\hline \multirow[t]{2}{*}{ Not performed surgery 9} & Yes & $7(13.2)$ & $46(86.8)$ & 19,8 & 8.80- & $<0.001$ \\
\hline & No & $490(75.2)$ & $162(24.8)$ & 7 & 44.89 & \\
\hline
\end{tabular}

Data are expressed as number of cases (\%) except when indicated.

* Size of vegetations measured in 598 patients. ISurgery indicated but not performed

Neurological complications are frequent and associated with a worse prognosis $[7,10,12]$. In this study, as found in others, about one quarter of patients developed neurologic complications [34]. We considered this complications only when it was clinically relevant, and not only like alterations in imaging techniques. Embolic phenomena are known to be more frequent at admission and during the first week, to occur despite proper medical treatment, and to be associated with worse prognosis, as was the case in our series.
Septic shock, which was developed by about $10 \%$ of our patients, was independently associated with increased mortality. This variable has only been studied previously in a report detailing IE patients admitted to the ICU [10], probably because it is not a frequent complication and cannot be evaluated as an independent risk factor in series with a low number of cases. As septic shock has been associated in general patients with mortality rate of about $50 \%$ [35], we consider that this variable helps to identify a high-risk subgroup of

Table 4 Multivariate analysis of prognostic factors of in-hospital mortality.

\begin{tabular}{lllll}
\hline Variable & $\boldsymbol{\beta}$ & OR & $\mathbf{9 5 \%} \mathbf{C l}$ & $\boldsymbol{P}$ \\
\hline Charlson comorbidity score & 0.217 & 1.24 & $1.14-1.35$ & $<0.001$ \\
\hline Prosthetic endocarditis & 0.688 & 1.99 & $1.26-3.14$ & 0.003 \\
\hline S. aureus aetiology & 0.760 & 2.13 & $1.30-3.50$ & 0.002 \\
\hline S. viridans group aetiology & -0.88 & 0.41 & $0.22-0.76$ & 0.005 \\
\hline Severe heart failure (Evolution) & 1.691 & 5.42 & $3.31-8.86$ & $<$ \\
\hline Neurologic manifestation & 0.657 & 1.93 & $1.24-2.99$ & 0.001 \\
\hline Septic shock & 1.445 & 4.24 & $2.33-7.70$ & $<001$ \\
\hline Perivalvular extension & 0.914 & 2.49 & $1.37-4.53$ & 0.003 \\
\hline Acute renal insufficiency & 0.525 & 1.69 & $1.09-2.60$ & 0.017 \\
\hline Surgical treatment & -0.685 & 0.50 & $0.30-0.84$ & 0.010 \\
\hline
\end{tabular}


patients that may benefit from aggressive management, such as early identification of severe sepsis and triggering evidence-based protocolised care [36].

Vegetations observed in echocardiography have been previously associated to a poor outcome [8] although one study found only large-sized vegetations to be an independent prognostic factor [6]. In our study, a vegetation size of $>20 \mathrm{~mm}$ almost reached statistical significance in univariate analysis but did not in multivariate analysis; a limitation of our study is that size of vegetations was not measured in all cases.

Perivalvular extension of infection (abscess and/or fistula) has traditionally been seen as an unfavourable prognostic factor $[7,37]$ although less so in more recent studies [25,38]. As in another recent large study [7] we found this complication to be an independent risk factor for mortality, which may be related to a higher post-surgical mortality associated with the intrinsic technically difficulties of these cases. This is a variable that identify another high-risk subgroup of patients, and must be suspected in presence of risk factors for this complications like prosthetic IE and aortic localization [25].

Our study have some limitations: First, changes in the clinical management of IE may have occurred during the long study period, although the inclusion of this variable in the multivariate model did not affect the results. Second, the majority of cases were included from referral centers so that the percentage of complicated cases may have been overestimated. However, other multicenter studies only include cases from reference centers and, even if represented by a small percentage, our series probably better reflects the overall clinical reality. Third, as TEE was not systematically performed, evaluation of echocardiographic data (size of vegetations, perivalvular extension) may be biased. And fourth, it is an observational study, so some results, such as the protective effect of surgery, must be interpreted cautiously.

\section{Conclusions}

We believe that our results may help identify IE patients at increased risk of in-hospital death by using data that are usually bedside available, which identify candidates for a more aggressive management in referral centers, with experience that includes active search for septic and hemodynamic complications and early surgical treatment when indicated.

\section{Acknowledgements}

The study was supported by the Ministerio de Sanidad y Consumo, Instituto de Salud Carlos III - FEDER, Spanish Network for the Research in Infectious Diseases (REIPI RD06/0008).

\section{Author details}

${ }^{1}$ Infectious Diseases Section, University Hospital Virgen Macarena, Sevilla. Spain. ${ }^{2}$ Infectious Diseases Unit, General Hospital Juan Ramón Jiménez, Huelva. Spain. ${ }^{3}$ Infectious Diseases Service, University Hospital Carlos Haya, Málaga. Spain. ${ }^{4}$ Infectious Diseases Section, University Hospital Virgen de la Victoria, Málaga. Spain. ${ }^{5}$ Internal Medicine Service, Hospital Costa del Sol, Marbella. Spain. ${ }^{6}$ Infectious Diseases Section, University Hospital Virgen de las Nieves, Granada. Spain. ${ }^{7}$ Infectious Diseases Service, University Hospital Virgen del Rocío, Sevilla. Spain.

\section{Authors' contributions}

JGA: carried out conception and design, analysis, interpretation of data and draft the manuscript. JRB: carried out design, analysis and revising the manuscript. FJMM: carried out analysis and interpretation of data, and revising the manuscript. JMR, AP, JR, JML, JTL, CHT: carried out acquisition of data and revising the manuscript. AA: carried out acquisition, analysis and interpretation of data, and revising it critically.

All authors have given final approval of the version to be published.

\section{Competing interests}

The authors declare that they have no competing interests.

Received: 13 May 2009

Accepted: 22 January 2010 Published: 22 January 2010

\section{References}

1. Durack DT: Evaluating and optimizing outcomes of surgery for endocarditis. JAMA 2003, 290:3207-3208.

2. Bouza E, Menasalvas A, Muñoz P, Vasallo FJ, Moreno MM, GarcíaFernández MA: Infective endocarditis - A prospective study at the end of the twentieth century. Medicine (Baltimore) 2001, 80:298-307.

3. Hoen B, Alla F, Selton-Suty C, Béguinot I, Bouvet A, Briaçon S, Casalta JP, Danchin N, Delahaye F, Etienne J, Le Moing V, Leport C, Mainardi JL, Ruimy $R$, Vandenesh F: Changing profile of infective endocarditis. Results of a 1-year survey in France. JAMA 2002, 288:75-81.

4. Tornos P, Lung B, Permayer-Miralda G, Barón G, Delahaye F, GohlkeBárwolf Ch, Butchart EG, Ravaud P: Infective endocarditis in Europe: lessons from the Euro Heart Survey. Heart 2005, 91:571-575.

5. Cabell CH, Jollis JG, Peterson GE, Corey GR, Anderson DJ, Sexton DJ, Woods CW, Reller LB, Ryan T, Fowler V: Changing patient characteristics and the effect on mortality in endocarditis. Arch Intern Med 2002, 162:90-94

6. Thuny F, Di Salvo G, Belliard O, Avierinos JF, Pergola V, Rosenberg V, Casalta JP, Gouvertnet J, Derumeaux G, larussi D, Ambrosi P, Calabro R, Riberi A, Collart F, Metras D, Lepidi H, Raoult D, Harle JR, Weiller PJ, Cohen A, Habib G: Risk of embolism and death in infective endocarditis: Prognostic value of echocardiography. A prospective multicenter study. Circulation 2005, 112:69-75.

7. Murdoch DR, Corey GR, Hoen B, Miró JM, Fowler V, Bayer A, et al: Clinical presentation, etiology, and outcome of infective endocarditis in the $21^{\text {st }}$ century. Arch Intern Med 2009, 169:463-473.

8. Chu VH, Cabell ChH, Benjamin DK, Kuniholm EF, Fowler V, Engemann J, Sexton DJ, Corey GR, Wang A: Early predictors of in-hospital deaths in infective endocarditis. Circulation 2004, 109:1745-1749.

9. Hasbun R, Vikram HR, Barakat LA, Buenconsejo J, Quagliarello VJ: Complicated left-sided native valve endocarditis in adults. Risk classification for mortality. JAMA 2003, 289:1933-194.

10. Mourviller B, Trouillet JL, Timsit JF, Baudot J, Chastre J, Regnier B, Gilbert C, Wolff $M$ : Infective endocarditis in the intensive care unit: clinical spectrum and prognostic factors in 228 consecutive patients. Intensive Care Med 2004, 30:2046-2052.

11. Wallace SM, Walton BI, Kharbanda RK, Hardy R, Wilson AP, Swanton RH: Mortality from infective endocarditis: clinical predictors of outcome. Heart 2002, 88:53-60.

12. Heiro M, Helenius H, Hurme S, Savunem T, Engblom E, Nikoskelainen J, Kotilainen P: Short-term and one-year outcome of infective endocarditis in adult patients treated in a Finish teaching hospital during 1980-2004. BMC Infectious Diseases 2007, 7:78.

13. Habib G, Tribouilloy C, Thuny F, Brahim A, Amazouz M, Remadi JP, Nadji G, Casalta JP, Coviaux F, Avieiros JF, Lescure X, Riberi A, Weiller PJ, Metras D, 
Raoult D: Prosthetic valve endocarditis: who needs surgery? A multicentre study of 104 cases. Heart 2005, 91:954-959.

14. Hayden JA, Côte P, Bombardier C: Effect of the quality of prognosis studies in systematic reviews. Ann Intern Med 2006, 144:427-437.

15. Granowitz EV, Longworth DL: Risk Stratification and bedside prognostication in infective endocarditis. JAMA 2003, 289:1991-1993.

16. Durack DT, Lukes AS, Brigth DK, et al: New criteria for diagnosis of infective endocarditis: utilization of specific echocardiographic findings. Am J Med 1994, 96:200-209.

17. Prendergast BD: Diagnostic criteria and problems in infective endocarditis. Heart 2004, 90:611-613.

18. Charlson ME, Pompei P, Ales KL, Makenzie CR: A new method of classifying prognosis comorbidity in longitudinal studies: development and validation. J Chron Dis 1987, 40:378-383.

19. Roques F, Nashef SAM, Michel P, Gauducheau E, Vicentiis C, Baudet E, Cortina J, David M, Fainechney, Gabrielle F, Gams E, Harjula A, Jones MT, Pintor PP, Salamon R, Thulin L: Risk factors and outcome in European cardiac surgery: analysis of the EuroSCORE multinational database of 19030 patients. Eur J Cardiothorac Surg 1999, 15:816-823.

20. Ho KK, Pinsky JL, Kannel WB, Levy D: The epidemiology of heart failure: the Framingham Study. J Am Coll Cardiol 1993, 22(4 Suppl A):6A-13A.

21. Bone RC, Balk RA, Cerra FB, Dellinger RP, Fein AM, Knaus WA, Schein RM, Sibbald WJ: American College of Chest Physicians/Society of Critical Care Consensus Conference: definitions for sepsis and organ failure and guidelines for the use of innovative therapies in sepsis. Crit Care Med 1992, 20:864-874.

22. Ben Ami R, Giladi M, Carmeli Y, Orni-Wasserlauf, Siegman-Igra Y: Hospitalacquired infective endocarditis: should the definition be broadened? Clin Infect Dis 2004, 38:843-850.

23. Anguita M, Torres F, Castillo JC, Delgado M, Mesa D, Ruiz M, Romo E, Arizón JM: Pronóstico a corto y largo plazo de la endocarditis infecciosa en pacientes no usuarios de drogas por vía parenteral. Resultados durante un período de 15 años (1987-2001). Rev Esp Cardiol 2006, 58:1188-1196.

24. Chirouze C, Cabell CH, Fowler VG, Khayat N, Olaison L, Miró JM, Habib G, Abrutyn E, Eykyn S, Corey GR, Selton-Suty C, Hoen B, the International Collaboration on Endocarditis Study Group: Prognostic factors in 61 cases of Staphylococcus aureus prosthetic valve Infective Endocarditis from the International Collaboration on Endocarditis Merged Database. Clin Infect Dis 2004, 38:1323-1327.

25. Graupner C, Vilacosta I, San Román JA, Ronderos R, Sarriá C, Fernández C, Mújica R, Sanz O, Sanmartín JV, González Pinto A: Periannular extensión of infective endocarditis. J Am Coll Cardiol 2002, 39:1204-1211.

26. Di Salvo G, Thuny F, Rosembberg V, Pergola V, Belliard O, Derumeaux G, Cohen A, larussi D, Giorgi R, Casalta JP, Caso P, Habib G: Endocarditis in the elderly: clinical, echocardiographic, and prognostic features. Eur Heart J 2003, 24:1576-1583.

27. Kourany W, Miro JM, Moreno A, Corey GR, Pappas PA, Abrutyn E, Hoen B, Habib G, Fowler VG, Sexton DJ, Olaison L, Cabell ChH, the ICE MD Investigator: Influence of diabetes mellitus on the clinical manifestations and prognosis of infective endocarditis: A report from the International Collaboration on Endocarditis-Merged Database. Scand I Infect Dis 2006, 38:613-619.

28. Pérez de Isla L, Zamorano JL, Almería C, Rodrigo JL, Piedra I, Aubele A: Endocarditis infecciosa en pacientes con hepatopatía crónica: valoración clínica y pronóstica. Rev Esp Cardiol 2003, 56:794-800.

29. Lalani T, Kanafani ZA, Chu VH, Moore L, Corey GR, Pappas P, Woods CW, Cabell CH, Hoen B, Selton-Suty C, Doco-Lecompte T, Chirouze C, Raoult D, Miro JM, Mestres CM, Olaison L, Eykyn S: Prosthetic valve endocarditis due to coagulase-negative staphylococci: findings from the International Collaboration on Endocarditis Merged Database. Eur I Clin Microbiol Infect Dis 2006, 25:365-368.

30. Fowler VF, Miró JM, Hoen B, Cabell CH, Abrutyn E, Rubistein , Corey GR, Spelman D, Bradley SF, Barsie B, Pappas PA, Anstrom KJ, Wray D, Fortes CQ, Anguera I, Athan E, Jhones Ph, Meer Van der JTM, Elliott TS, Levine DP, Bayer AS, for the ICE investigator: Staphylococcus aureus endocarditis. A consequence of medical progress. JAMA 2005, 293:3022-3061.

31. Nadji G, Remadi JP, Coviaux F, Mirode AA, Brahim A, Enriquez-Sarano M, Tribouilloy C: Comparison of clinical and morphological characteristic of Staphylococcus aureus endocarditis with endocarditis caused by other pathogens. Heart 2005, 91:932-937.
32. Vikram HR, Buenconsejo J, Hasbun R, Quagliarello VJ: Impact of valve surgery on 6-month mortality in adults with complicated, left-side native valve endocarditis: a propensity analysis. JAMA 2003, 290:3207.

33. Tleyjeh IM, Kashour T, Zimmerman V, Steckelberg JM, Wilson WR, Baddour LM: The role of valve surgery in infective endocarditis management: A systematic review of observational studies that included propensity score analysis. Am Heart J 2008, 156:901-909.

34. Heiro M, Nikoskelaimen J, Engblom E, Kotilaimen E, Marttila R, Kottilaimen P: Neurologic manifestations of infective endocarditis. A 17-year experience in a teaching hospital in Finland. Arch Intern Med 2000, 160:2781-2787.

35. Vincent JL, Sakr Y, Sprung CL, Ranieri M, Reinhart K, Gerlach H, et al: Sepsis in European intensive care units: results of the SOAP study. Crit Care Med 2006, 34:344-353.

36. Nguyen HB, Rivers EP, Abrahamian FM, Moran GJ, Abraham E, Trzeciak SH, Bryant H, David T, Huang DT, Osborn T, Stevens D, Talan DA, Emergency Department Sepsis Education Program and Strategies to Improve Survival (ED-SEPSIS) Working Group: Severe sepsis and septic shock: Review of the literature and emergency department management guidelines. Ann Emerg Med 2006, 48:28-54.

37. San Román JA, Lopez J, Vilacosta I, Luaces M, Sarriá C, Revilla A, Ronderos R, Stoerman W, Gómez I, Fernández-Avilés F: Prognostic stratification of patients with left-sided endocarditis determined at admission. Am J Med 2007, 120:e1-369.

38. Choussat R, Thomas D, Isnard R, Michel PL, Lung B, Hanania G, Mathieu P, David M, du Roy de Chaumaray T, De Gevigney G, Le Breton H, Logeais Y, Pierre-Justin E, Riberolles C, Morvan Y, Bischoff N, Participants in the Perivalvular Abscesses French Multicentre Study: Perivalvular abscesses associated with endocarditis. Clinical features and prognostic factors of overall survival in a series of 233 cases. Eur Heart J 1999, 20:232-241.

\section{Pre-publication history}

The pre-publication history for this paper can be accessed here:http://www. biomedcentral.com/1471-2334/10/17/prepub

doi:10.1186/1471-2334-10-17

Cite this article as: Gálvez-Acebal et al:: Prognostic factors in left-sided endocarditis: results from the andalusian multicenter cohort. BMC Infectious Diseases 2010 10:17.

\section{Publish with Bio Med Central and every scientist can read your work free of charge}

"BioMed Central will be the most significant development for disseminating the results of biomedical research in our lifetime. "

Sir Paul Nurse, Cancer Research UK

Your research papers will be:

- available free of charge to the entire biomedical community

- peer reviewed and published immediately upon acceptance

- cited in PubMed and archived on PubMed Central

- yours - you keep the copyright
BioMedcentral 